\title{
LA CONTRAFACTUALIDAD DE PASADO. ¿POR QUÉ HABLAMOS SOBRE LO QUE NO OCURRIÓ NI VA A OCURRIR?
}

\section{THE CONTRAFACTUALITY OF THE PAST. WHY DO WE TALK ABOUT WHAT DIDN'T HAPPEN OR WILL HAPPEN?}

\author{
Angelita Martínez ${ }^{1}$ \\ Universidad Nacional de La Plata \\ angemalucea@gmail.com \\ Adriana Speranza ${ }^{2}$ \\ Universidad Nacional de Moreno/CONICET \\ Universidad Nacional de La Plata \\ paglispe@gmail.com
}

\begin{abstract}
Resumen
El análisis de la variación morfosintáctica (García, 1985; 1997) constituye, no solo una valiosa herramienta metodológica para explorar el funcionamiento del lenguaje, sino, también, un insumo didáctico en el ámbito de la enseñanza de las lenguas y de las variedades lingüísticas. Desde esa perspectiva, en este trabajo, nos centramos en el uso normativo variable de las formas del pluscuamperfecto del modo subjuntivo, en mensajes contrafactuales de pasado. Las gramáticas sostienen, en general, que el español americano manifiesta una preferencia por las formas en - ra y relegan el empleo de las formas en -se a la lengua escrita (Nueva gramática de la lengua española (NGLE), 2010, p.457). Sin embargo, el análisis detenido de su empleo en distintos géneros y variedades del español, tanto peninsular (Lara Bermejo, 2019) como americano, nos advierte de la presencia de la alternancia de ambas formas, explotada con mayor o menor frecuencia relativa, a la luz del contexto, en relación con necesidades comunicativas de los usuarios. Dentro de ese proyecto mayor, que confronta variedades lingüísticas y usos variables, nos detenemos, en este artículo, en el análisis de una variedad peninsular, a través de la novela Cinco horas con Mario de Miguel Delibes. El análisis de la distribución de las formas observadas en dicho corpus nos permite indagar las motivaciones que llevan al escritor, en el contexto de la novela, a explotar la variación. Asimismo, los resultados del análisis constituyen un aporte a la conformación de estrategias pedagógicas.
\end{abstract}

Palabras clave: Contrafactualidad - Variación morfosintáctica - Variedades lingüísticas - Enseñanza de lenguas 


\begin{abstract}
The analysis of morphosyntactic variation (García, 1985; 1997) serves not only as a valuable methodological tool to explore the workings of language, but also as a didactic input in language and linguistic varieties teaching contexts. From this perspective, in this article we focus on the variable prescriptive use of the past perfect, subjunctive mood forms in counterfactual messages in the past. Generally, grammars posit that Latin American Spanish shows a preference for $-r a$ forms, and, consequently, grammars relegate the-se forms to written language (Nueva Gramática de la Lengua Española, (INGLE), p.457). However, detailed analysis of its use in different genres and Spanish varieties, both peninsular (Lara Bermejo, 2019) and Latin American, inform us of the presence of alternation of those forms, exploited with greater or lesser relative frequency, in the light of the context, based on the communicative needs of users. Within that larger project -confronting linguistic varieties and variable use -, the focus of this article is the analysis of a peninsular variety through the novel Cinco Horas con Mario, by Miguel Delibes. The analysis of forms distribution observed in said corpus allows us to inquire about the motivations leading the writer, in the context of the novel, to exploit variation. Furthermore, the results of the analysis constitute a contribution to the makeup of pedagogical strategies.
\end{abstract}

Keywords: Counterfactual messages - Morphosyntactic variation - Linguistic varieties - Language teaching 


\section{INTRODUCCIÓN}

Las gramáticas de uso han sostenido que el español americano manifiesta una preferencia por la forma modo y tiempo -ra, aunque la forma - se aparece en la lengua escrita (NGLE, 2010). Sin embargo, el análisis detenido de su empleo en distintas variedades del español, tanto peninsular (Lara Bermejo, 2019) como americano, nos permite advertir que ambas formas están muy vigentes y son explotadas con mayor o menor frecuencia relativa, a la luz del contexto, en relación con las necesidades comunicativas de los usuarios. Para sostener esta hipótesis, en el marco de un proyecto mayor en el que se comparan manifestaciones discursivas de distintas variedades de español de los siglos XX y XXI, en esta ocasión hemos analizado la novela Cinco horas con Mario del autor español Miguel Delibes donde se observa un uso alternante muy prolífico de ambas formas. Las distribuciones observadas requieren de un análisis que permita postular cuáles son las razones que llevan al escritor, en este caso, a seleccionar ambas formas en variación.

El juego intraparadigmático y la confrontación de variedades de una lengua en lo que corresponde a la explotación que los hablantes hacen de los paradigmas (Martínez, 2015) podrían constituir insumos relevantes para un proyecto de gramática explicativa. El artículo, además de esta introducción, recurre a delinear el problema de investigación para después rastrear algunos antecedentes y detenerse en aspectos teóricometodológicos que guían el análisis que tiene como objetivo explicar la alternancia.

La variación morfosintáctica: una herramienta didáctica esencial

El lenguaje humano es, esencialmente, un instrumento de comunicación. La posibilidad de transmitir mensajes que manifiesten necesidades comunicativas se ve atravesada en todos los niveles lingüísticos por procesos culturales. En efecto, nuestro trabajo nos ha llevado a la conclusión de que la morfosintaxis se halla, muchas veces, modelada por la cultura (García, 1995; Martínez, 2000, 2019; Speranza, 2014, 2020).

En ese sentido, los resultados del estudio de la variación morfosintáctica pueden constituirse en una herramienta poderosa para la enseñanza de la lengua desde un enfoque comprensivo.

Un trabajo que intente descubrir qué necesidades comunicativas subyacen a la elección de las formas en variación y tenga en cuenta la relación del contexto que las anida, a la luz del aporte significativo de las mismas, puede ofrecer a los estudiantes, tanto de lengua materna como de segunda lengua, una explicación de las rutinas comunicativas.

\section{El discurso contrafactual: Pluscuamperfecto del subjuntivo}

Es evidente que el empleo de los llamados modos y tiempos verbales constituye un desafío para quienes deseen entender su gran complejidad. En efecto, si nos internamos en los usos discursivos de los tiempos verbales nos enfrentamos, incluso, con formas 
que alternan en la conformación de un mismo mensaje. Pero esa alternancia, que ha sido reconocida por muchos estudiosos de la lengua española como selecciones arbitrarias, es solo aparente. Un estudio de variación que, como hemos dicho, pone en relación significados y contextos, deja ver que ambas formas coexisten porque remiten a mensajes diferentes.

Este hecho, magistralmente expuesto por García (1985; 1997), nos conduce, en este caso, a investigar dos formas que la tradición y la enseñanza han abordado como sinónimas. Nos referimos al llamado pretérito pluscuamperfecto del modo subjuntivo, empleado para expresar la contrafactualidad que, como sabemos, se manifiesta con dos formas, alternantes (Martínez, 1991, 1993), tal como podemos observar en el ejemplo que sigue, en el que el hablante recurre, en el mismo contexto, a las dos opciones:

1. Eso si no sois vosotros los que buscáis la ocasión, que bueno está Madrid, hijo, una vergüenza, que a partir de las ocho hay más fulanas por las calles que personas decentes, que ha sido un error, ya ves tú, cerrar las casas, que yo, todo lo contrario, las hubiera pintado de colores bien chillones para que nadie se llamase a engaño, y a las pelanduscas las hubiese encerrado allí, pero a cal y canto, ¿eh?, que no pudieran ver ni la luz del sol, que no merecen otra cosa, por mucho que tú vengas con que nadie lo es por gusto, que los hombres puestos a disculpar resultáis imposibles. (Delibes, 1966, p.95)

El par mínimo representado en (1) es una muestra de la alternancia de las formas del pluscuamperfecto de subjuntivo. El personaje, en este caso Carmen, remite a dos intenciones que nunca llegaron a concretarse: las hubiera pintado y las hubiese encerrado. Distintas señales del contexto nos permiten entender la relevancia de la alternancia. La referencia del clítico en uno y otro caso, el aporte significativo de sendos participios, así como los modalizadores del resto del contexto nos ofrecen claves comunicativas que apoyan una hipótesis semántica sobre las formas en cuestión.

\section{El corpus}

Hemos seleccionado para este trabajo la novela Cinco horas con Mario de Miguel Delibes, autor vallisoletano, escrita en el año 1966. Toda la obra es una hipótesis respecto de diferentes circunstancias de la vida de Carmen junto a su esposo Mario. A lo largo de la novela, la protagonista monologa frente al cuerpo yacente de su esposo y repasa la vida compartida. Construye un gran reproche por medio del cual despliega su evaluación sobre las acciones del difunto, la sociedad de la época y la familia. El despliegue argumental se organiza alrededor de la opinión que expresa Carmen respecto de los hechos:

2. Yo no sé, a veces me da por pensar que tú hubieses encajado con Esther, y otras que no, yo creo que demasiado parecidos tampoco resulta, no sé, es un lío, pero lo cierto, Mario, no nos engañemos, es que tú no eres un tipo de hombre de gustar a las mujeres, [...]. (Delibes, 1966, p.111) 
Gran parte del monólogo de Carmen se apoya en el discurso contrafactual y, en consecuencia, nos entrega un importante caudal de conocimientos sobre el empleo de las formas que son propias de ese aspecto del discurso.

En lo que respecta a la distribución de las formas, el corpus muestra una alternancia claramente a favor de la forma -ra, tal como se observa en el cuadro que sigue:

\section{Tabla 1}

Distribución de las formas pretérito pluscuamperfecto del subjuntivo

\begin{tabular}{|c|c|c|c|c|c|}
\hline & \multicolumn{4}{|c|}{ Formas en variación } & \multirow[t]{2}{*}{ Totales } \\
\hline & & $-r a$ & & & \\
\hline Cinco horas con Mario & & $81 \%$ & & $19 \%$ & $\begin{array}{l}113 \\
100 \%\end{array}$ \\
\hline
\end{tabular}

\section{Antecedentes}

Muchos son los trabajos que se han llevado a cabo sobre contrafactualidad en el español. Para los objetivos de este artículo, nos interesan particularmente dos de las conclusiones a las que los investigadores han arribado porque consideramos que pueden ser discutidas.

En algunos estudios se ha considerado que las dos variantes se emplean indistintamente y se ha reducido el análisis del pluscuamperfecto del subjuntivo a cuestiones de estilo. Sin embargo, si observamos el uso real de la lengua, podemos comprobar que los hablantes o escribientes reiteran la forma así como recurren a la alternancia a partir de motivaciones comunicativas que atienden a necesidades propias más que al mero interés de evitar la redundancia.

En el ejemplo siguiente damos cuenta de la repetición de la forma -ra en un mismo párrafo:

3. Te doy mi palabra, Mario, pero cada vez que te veía al solazo en el banco de enfrente de casa, con un periódico, que entonces me empezaste a gustar, ya ves, yo creo que por eso, pensaba, "ese chico me necesita y debe ser muy apasionado", que me hacía ilusiones, fijate, sin fundamento, de acuerdo, pero a mí, y te hablo con el corazón en la mano, me hubiera gustado tener que pararte alguna vez los pies, no te digo como a Evaristo o a Galli, que entonces ni me hubiera casado, seguro, pero sí un poquito de pasión, ya ves Maximino Conde con la hijastra, y a su edad, completamente trastornado, hasta el punto de que ella, Gertrudis, se tuvo que largar al extranjero sin hacer ni el equipaje, que a saber allí, porque después de todo Maximino era su padrastro y alguna delicadeza hubiera tenido y, entiéndeme, no es que le disculpe ni muchísimo menos. (Delibes, 1966, p.90)

Por el contrario, otras veces el emisor recurre al empleo alternante de ambas formas, tal como puede verse en (4): 
4. Pobre idea tienes tú de Nuestro Señor, cariño, "le hemos desfigurado; le hemos desfigurado", y ¿no eres tú el primero? Por si te interesa saberlo, Mario, Cristo no hubiese tenido nunca un hermano rojo, ni un padre prestamista y, de tenerlos, ten la seguridad de que no se hubiera quedado tan fresco, ni hubiese alzado el gallo, ni, por descontado, hubiera hablado de la caridad como tú hablaste, que hay que ver la pobre Bene la ilusión que tenía, que se pasó semanas enteras rondándome, "Mario es el más indicado; si él quisiera", que a mí me sorprendió, palabra, lo pronto que me dijiste que sí. (Miguel Delibes, 1966, p. 84)

Por otra parte, es habitual que en los estudios sobre el tema se insista en la correlación temporal de la condicionalidad que, en el caso de las emisiones contrafactuales, indica el empleo del condicional compuesto en la apódosis.

Llamativamente, a lo largo de todo nuestro cuerpo de datos no hemos hallado emisiones condicionales cuya apódosis contenga el condicional compuesto. Por su parte, las prótasis de las condicionales alternan el empleo de las formas -ra y -se del pluscuamperfecto subjuntivo, tal como vemos en los ejemplos siguientes:

5. ¿Te acuerdas, Mario? Y eso que en una clínica es más difícil, pero no fallaba, todos los días camisón limpio, y las flores, que en esa situación parece que no está una para nada, pues ya veías, daba gusto estar allí, y es lo que yo digo, si mamá, que en paz descanse, hubiera llegado a los extremos de tu padre, hubiese dejado de comer, me apuesto lo que quieras, antes moriría de hambre que hacérselo, date cuenta. (Delibes, 1966, p. 65)

6. Te digo mi verdad, si de algo me arrepiento, es de haber estado veintitrés años pendiente de ti, como una mártir, que si yo hubiese sido más dura, otro gallo me cantara. (Delibes, 1966, p.21)

En el caso de las apódosis, presentan mayoritariamente la forma -se, como se observa en (5). Sin embargo, también encontramos ejemplos de apódosis en -ra:

7. Pero tú, parece que lo tienes a gala, hijo, porque si de entrada te vas derecho a Filguera y le dices sin más, "pues tiene usted razón, me he obcecado", todo hubiera cambiado, seguro, y ni él, ni Josechu Prados, ni Oyarzun, nos hubieran negado el piso, me juego la cabeza, lo que ocurre es que tú siempre has querido las cosas por las bravas, que confundes la educación con el servilismo. (Delibes, 1966, p. 69)

Los casos en los que el emisor opta por -ra en la apódosis no aparecen en correlación con la prótasis en -se, es decir, la combinación complementaria a la observada en (5). La selección de -ra en estos contextos acompaña, en la mayor parte de los casos, la presencia del presente en la prótasis tal como se observa en (7). Esta combinación resulta coherente, en términos pragmáticos y comunicativos, con el significado de las formas que postularemos más adelante.

Frente a estas dos observaciones, desde una perspectiva que considera que la sintaxis se halla motivada semántica y pragmáticamente, cabe preguntarse: ¿por qué el hablante 
o escribiente recurre, de manera alternante, a dos formas, para construir el discurso contrafactual de pasado, y qué motivación lo lleva a optar por una o por la otra?

Para encontrar respuestas consideramos necesario hacer un análisis de la alternancia observada. Un análisis de variación que nos permita explicar la distribución de las formas en cuestión.

\section{El marco teórico y metodológico}

Dentro del marco teórico correspondiente al estudio de la variación morfosintáctica que hemos propuesto, adoptamos un posicionamiento que toma en consideración las críticas de García (1985) a los criterios de variación de la sociolingüística laboviana y nos alineamos con su posición al respecto, explicitada en García (1997).

En efecto, para nuestro análisis nos apoyamos en la siguiente definición de variación que nos ofrece García (1997):

La variation, par définition, présuppose l'equivalence communicative, d'où la comparabilité d'unités linguistiques distinctes, et leur intersection distributionnelle (partielle). [...] comme la syntaxe est, par définition, ouverte, les environnements pertinents ne peuvent être ni dé nis avec précision, ni énumérés exhaustivement. Les environnements pertinents pour la DC phonologique et allomorphique sont, par définition, partie de la langue; mais ceux que son pertinents pour la variation syntaxique sont dans la parole. (p. 32)

Dicha definición establece, como dijimos, el alejamiento de los estudios sociolingüísticos tradicionales para manifestarse mediante una concepción del fenómeno totalmente opuesta:

Ces deux conceptions opposées conduisent à des approches très diférentes de la variation syntaxique. Définir la variation comme "dire la même chose de façon différente" (Labov 1970, p. 34 fn. 7 ; 1972, p. 271) présuppose non seulement l'ádhésion aux catégories universelles traditionnelles, mais aussi l'hypothèse que celles-ci restent constantes dans le temps. L'alternance entre variantes est donc vue comme linguistiquement libre et communicativement équivalente pour la syntaxe comme pour la variation libre phonétique.

Sinon, on admet que toute intersection communicative est référentielle, plus que cognitive ou linguistique, et réalisée avec des moyens linguistiquement non équivalents. Loin d'être "différentes choses sur la même chose", les variantes syntaxiques seraient "des façons de dire différentes choses sur le même référent", auxquelles les locuteurs recourent à cause des perspectives différentes qu'elles o rent. (García 1997, p. 34)

Desde esta perspectiva, que propicia una metodología cualitativa y cuantitativa sobre corpus genuino, en este trabajo presentamos, algunas cuestiones preliminares de frecuencia de uso de las formas para focalizar, fundamentalmente, los aspectos 
cualitativos del análisis, puesto que son los que nos serán útiles al objetivo propuesto en relación con la enseñanza de una gramática explicada.

\section{El análisis de los datos}

\section{La hipótesis sobre el significado de las formas}

Las formas -ra y -se se corresponden con dos de los llamados tiempos verbales del modo subjuntivo: el pretérito imperfecto y el pretérito pluscuamperfecto. En ambos contextos, las mismas formas permiten inferir una dimensión no factual. El pretérito imperfecto manifiesta una menor posibilidad de ocurrencia de la acción contenida en el lexema verbal, una menor "posibilidad epistémica" de realización de la acción asignada por el hablante (Martínez, 1991, 1993; Martínez et al., 1998). Sin embargo, en lo que corresponde al imperfecto, la forma -ra manifiesta un grado de mayor certeza y posibilidad en relación con la forma -se, que indica un menor nivel de certeza y posibilidad (Speranza, 2020).

En el caso que estamos considerando, el pretérito pluscuamperfecto, se suma un participio pasado, y, como resultado, la dimensión es contrafactual. La alternancia, en este caso, corresponde a la explotación de los mismos significados para expresar una evaluación de la asignación de ocurrencia (chance) que otorga el hablante a lo que no sucedió ni va a suceder. La forma -ra expresa mayor posibilidad de ocurrencia asignada mientras que la forma -se manifiesta la menor posibilidad de ocurrencia asignada.

La postulación de estos significados es coherente con el hecho de que las formas -ra y -se mantienen su significado etimológico: la forma -ra deriva del indicativo latino y, por lo tanto, expresa, relativamente, mayor asignación de ocurrencia, mientras que la forma -se deriva del subjuntivo latino por lo que resulta la más adecuada para evaluar el evento con menor posibilidad de ocurrencia (Martínez, 1993, p. 202).

\section{Factores contextuales y su incidencia en la alternancia}

\section{La estructura de la emisión}

A la luz de esta hipótesis y dado que las formas en estudio se presentan tanto en estructuras condicionales como en otro tipo de estructuras (oraciones principales o proposiciones sustantivas, en general), presentamos una tabla en la que medimos la frecuencia relativa de una u otra forma en relación con el tipo de emisión. 


\section{Tabla 2}

Frecuencia relativa de -ra vs. -se en relación con la estructura de las emisiones

\begin{tabular}{|c|cc|cc|cc|}
\hline & \multicolumn{2}{|c|}{- ra } & \multicolumn{2}{c|}{-se } & \multicolumn{2}{c|}{ Totales } \\
\hline Condicionales & 27 & $84 \%$ & 5 & $16 \%$ & 32 & $100 \%$ \\
\hline Otras & 65 & $80 \%$ & 16 & $20 \%$ & 81 & $100 \%$ \\
\hline Totales & $\mathbf{9 2}$ & $\mathbf{8 0 \%}$ & $\mathbf{2 1}$ & $\mathbf{2 0 \%}$ & $\mathbf{1 1 3}$ & $\mathbf{1 0 0 \%}$ \\
\hline
\end{tabular}

Nota: o.r. $=1.25$

Los resultados obtenidos en esta tabla dan cuenta de que el tipo de estructura (condicional vs. otras) no constituye un factor influyente en la selección de las formas. La frecuencia relativa del uso, tan pareja para ambas variantes, nos permite homogeneizar el corpus y abordar todos los casos sin discriminar la estructura de las emisiones.

\section{El aporte semántico del participio}

Recurrimos, entonces, a un nuevo análisis cualitativo de los contextos en los que las formas se manifiestan en variación que nos lleva a contemplar el aporte significativo del participio pasado. Hemos observado:

a) Participios o construcciones de connotación positiva

b) Participios o construcciones de connotación negativa

Creemos que, coherentemente con el significado propuesto para las formas, los participios o construcciones participiales de connotación positiva favorecen la forma en -ra como señal de evaluación de alta oportunidad de ocurrencia, por el contrario, las connotaciones negativas favorecen la presencia de la forma -se.

\section{Participios o construcciones de connotación positiva}

La evaluación que Carmen realiza a partir de la no factualidad también se expresa a través de la selección léxica de los verbos. En el marco de su reconstrucción aparecen acciones en las que el significado positivo del participio es explícito:

8. Aun con los ojos cerrados y preservados por el antebrazo, Carmen sigue viendo desfilar rostros inexpresivos como palos cuando no deliberadamente contristados: "Lo dicho"; "Mucha resignación"; "Cuídate, Carmen, los pequeños te necesitan"; “¿A qué hora es mañana la conducción?" Y ella: "Gracias, Fulano", o "Gracias, Mengana” y ante las visitas eminentes: "iCuánto le hubiera alegrado al pobre Mario verle por aquí!". (Delibes, 1966, p.3)

En otros casos, la construcción se hace más compleja y el carácter positivo surge de distintos elementos del entorno: 
9. Yo le hubiera hecho con gusto el boca a boca, no hubiera tenido el menor reparo, que otras dicen que qué asco, yo no, que todo menos dejarle irse así, fíjate, pero si te digo mi verdad no lo he visto más que una vez en el NO-DO y no me atreví, porque son de esas cosas, ya sabes, que ni prestas atención, como quien ve a los bomberos, a mí plin, eso conmigo no reza, no sé cómo decirte, lo último que se te ocurre. "El corazón es muy traicionero, ya se sabe". (Delibes, 1966, p.5)

10. Todo hubiera ido entonces mucho mejor, estoy segura, y no es que me queje, entiéndeme, que ya sé que es una tontería pensar estas cosas, porque si tú hubieras sido hijo de mamá, por lo menos seríamos medio hermanos, a ver, y no hubiéramos podido casarnos, que todo eso de las sangres iguales y el factor R-H me aterra, fíjate, de siempre, [...] (Delibes, 1966, p.96)

En la misma línea, aparecen contextos en los que la evaluación positiva incluye la expresión de deseos:

11. Porque tú sabes escribir, querido, te lo digo y te lo repito, lo único los argumentos, que yo no sé qué maña te dabas, que ni escogidos con candil, eso cuando se te entendía, que cuando te ponías a hablar de estructuras y cosas de esas me quedaba in albis, te lo prometo, icon lo que a mí me hubiera gustado que escribieras libros de amor! (Delibes, 1966, p.18)

Como hemos planteado, estas emisiones resultan juicios sobre hechos del mundo que no sucedieron ni sucederán. Nos hallamos ante reflexiones sobre eventos sin posibilidad de realización. Sin embargo, el enunciador realiza una reconstrucción discursiva asignándoles mayor oportunidad de realización en un plano hipotético. En este marco tiene lugar la expresión de los deseos; expresión que, al igual que el resto, se ve acompañada, preferentemente, por la selección de la forma -ra a partir del aporte que su significado realiza a los contextos que hemos presentado.

\section{Participios o construcciones de connotación negativa}

Las emisiones en las que aparecen participios o construcciones participiales de connotación negativa favorecen la presencia de la forma -se y muestran la correlación entre el significado y las características del contexto propuesto, como hemos anticipado. El procedimiento se resuelve de la misma manera que hemos observado respecto de la distribución de la variante-ra: aparecen ejemplos con lexemas explícitamente negativos, tal como se observa en los siguientes ejemplos.

12. Dime la verdad, ¿te correspondía eso a ti? Desengáñate, Mario, cariño, la bici no es para los de tu clase, que cada vez que te veía se me abrían las carnes, créeme, y no te digo nada cuando pusiste la sillita en la barra para el niño, te hubiese matado, que me hiciste llorar y todo. (Delibes, 1966, p.19) 
13. [...] pero cuando empezaste a disparar botellas de champán, desde el balcón, contra las farolas, te hubiese matado, fíjate, que no son formas, que yo cualquier cosa antes que perder los modales, es cuestión de educación, en casa me lo grabaron a fuego y ya ves. (Delibes, 1966, p.23)

Por otra parte, la connotación negativa también se observa desplegada en el contexto inmediato:

14. [...] Mario, que me quitó la palabra de la boca, que ni hablar podía, estaba desquiciada, cariño, tienes que hacerte cargo, solo quiero que me comprendas, ¿̇oyes?, porque aunque hubiese hecho algo malo no era yo, puedes estar seguro, que la persona que estaba allí no tenía nada que ver conmigo, solo faltaría, pero no pasó nada, nada de nada, en absoluto, te lo juro por lo que más quieras, Mario, créeme, [...]. (Delibes, 1966, p.116)

15. [...] y tú entonces estabas bien, que lo otro fue mucho más tarde y no es que yo diga que lo otro fuese nada importante, que va, ni muchísimo menos, una pataleta de niño consentido, porque tú me dirás, si no te dolía nada, ni tenías fiebre, ¿qué clase de enfermedad era esa? Te digo mi verdad, si de algo me arrepiento, es de haber estado veintitrés años pendiente de ti, como una mártir, que si yo hubiese sido más dura, otro gallo me cantara. (Delibes, 1966, p.21)

\section{Un nuevo factor discursivo: la justificación de la predicción}

Hemos visto, hasta el momento, que el factor estructural no tiene incidencia en la selección de las formas mientras que el factor semántico, es decir, el aporte significativo del participio, incide consistentemente, aunque no de manera exhaustiva, en dicha selección. Vamos a probar, entonces, un nuevo factor, esta vez de orden discursivo: la justificación de la predicción a través de las opiniones de Carmen respecto del contenido contrafactual emitido.

Entendemos por opinión "un juicio intelectivo tributario de un cálculo referido a la probabilidad de los hechos del mundo" (Charaudeau y Maingueneau, 2005, p.413). En este marco, observamos que las opiniones de Carmen se ven acompañadas por su apreciación sobre los hechos. Por su parte, entendemos por apreciación una reacción afectiva del sujeto -positiva o negativa- frente a un hecho (Charaudeau y Maingueneau, 2005). Así, se elabora una estrategia argumentativa por la cual el hablante expresa una opinión reforzada por su valoración, a modo de garantía, por medio de marcas que manifiestan la reacción afectiva sobre la opinión contenida en el enunciado.

En efecto, en el curso del monólogo de Carmen, los enunciados contrafactuales que ella pronuncia están acompañados, muchas veces, por la justificación que la misma Carmen hace sobre su evaluación de lo que no pasó. Dicha justificación se encuentra motivada por factores que intentaremos delinear a continuación. 


\section{Justificación subjetiva}

Las formas de justificación observadas en el texto expresan la evaluación que Carmen realiza sobre los hechos; evaluación por la cual se construye como sujeto discursivo a través de la expresión de su subjetividad. Entendemos por subjetividad la capacidad del locutor de presentarse como sujeto en el discurso a partir de la apropiación de distintos recursos que la lengua pone a su disposición (Charaudeau y Maingueneau, 2005). En relación con el uso de los recursos lingüísticos, creemos que la selección de las formas -ra y-se del pluscuamperfecto del subjuntivo constituye una de las estrategias de justificación. En este caso, la justificación por la cual Carmen expresa su opinión y apreciación de los hechos se ve acompañada por la selección de la forma-ra, a partir del significado básico que hemos postulado: asignación de mayor oportunidad de realización de la acción contenida en el evento.

Tal como sostiene Lyons (1997): "[...] el yo que expresa el agente locutivo es el producto de las funciones sociales e interpersonales que él o ella ha desempeñado en el pasado y que se manifiestan, de un modo socialmente identificable, en el papel que él o ella desempeña en el contexto del enunciado" (p.362). En esta línea, Carmen se construye a sí misma a partir de una serie de argumentos expuestos en su análisis. De esta manera, apela a diferentes elementos para construir su justificación. Veamos algunos ejemplos.

16. Y luego, que perdías pie, y que sentías vértigos solo de pensar que estabas sobre una bola suspendida en el infinito, que yo se lo decía a Valen, "qué cosas dice, Valen; está para encerrar", y, en vista de eso, a tumbarte en la cama, que menuda vida te pegaste a costa de los nervios, hijo, que lo que Antonio decía, a ver, por su gusto, pero él no es más que una pequeña pieza de una gran máquina, se debe al Ministerio, y lo único, permiso por enfermedad, con la mitad del sueldo, lo que nos faltaba, que tampoco te hubiera matado, creo yo, un par de horas en el Instituto a decir lo mismo de siempre. (Delibes, 1966, p.102)

En este caso, Carmen evalúa el accionar de Mario desde su perspectiva sobre la responsabilidad del varón como sostén económico de la familia burguesa a través de su desempeño en el trabajo, reproche constante a lo largo de toda la novela. El trabajo para Carmen se organiza a través de horarios fijos, en espacios definidos. En (16), Carmen reproduce la idea del trabajo como esfuerzo físico capaz de ser medido en términos de tiempo: "Que tampoco te hubiera matado, creo yo, un par de horas en el Instituto".

Toda la argumentación observada en el ejemplo anterior se ve reforzada por la garantía de la voz enunciadora: "creo yo". En este caso, la subjetividad se consolida a partir de la incorporación de elementos de carácter epistémico que permiten el despliegue de la perspectiva de la protagonista al igual que en el ejemplo que sigue:

17. [...] ya ves tú, que lo único que no decíais del dinero era la pura verdad, Mario, que es necesario, y mejor nos hubiera ido si en vez de hablar tanto del dinero os hubierais puesto a ganarlo, como yo digo. Porque tú sabes escribir, querido, te lo digo y te lo 
repito lo único los argumentos, que yo no sé qué maña te dabas, que ni escogidos con candil, eso cuando se te entendía, que cuando te ponías a hablar de estructuras y cosas de esas me quedaba in albis, [...]. (Delibes, 1966, p.18)

En (17) nuevamente Carmen apela a su compromiso epistémico a través de la primera persona: "como yo digo", "te lo digo y te lo repito". El mismo procedimiento se observa en el siguiente ejemplo:

18. Así, Mario, como lo estás oyendo, te lo juro, como si lo hubiera presentido, y yo, la verdad, que se mueran del corazón los hombres de negocios, que de un telefonazo pueden ganar o perder millones, lo comprendo, pero que te mueras del corazón tú, un hombre que jamás se ha preocupado del dinero, que tiene una mujer que de dos saca cuatro, un hombre al que no le ha faltado nada, que no es que vayas a decir esto o lo otro, no hay derecho, la verdad, no hay derecho y no hay derecho (Delibes, 1966, p.86).

En este caso, Carmen confirma su compromiso y suma, a la selección de la primera persona, un acto ilocutivo específico: el juramento; acto con el cual fortalece su autoridad epistémica, todo esto acompañado por la selección de la forma -ra a partir del significado que aporta, tal como hemos postulado.

\section{Justificación argumentativa}

Otros ejemplos muestran el despliegue de una justificación más compleja por la cual la subjetividad de Carmen se hace explícita en la construcción de argumentaciones que acompañan la evaluación de su hipótesis:

19. A ti te dio rabia caerte de la bicicleta, ia que sí!, que, yo Comisario, hubiera hecho lo propio, "no hay contradenuncia mientras un médico no certifique", que a cualquier otro le hubiera bastado, pero tú no, duro, a la Casa de Socorro, ihala!, a molestar a las cuatro de la madrugada, que tampoco son horas, y que digas que te tropezaste con un tipo a medida, que el medicucho aquel fue el que te metió en cantares que si "hematoma producido por los nudillos de una mano", que también hace falta cuajo, vamos, que lo que Filgueira decía, "el propio pedal", a saber, eso no puede averiguarse, pero tú, venga, la contradenuncia, abuso de autoridad, una monomanía, [...] (Delibes, 1966, p.100).

En este caso, Carmen elige encabezar la argumentación adoptando el punto de vista del antagonista de Mario en el evento, el Comisario: "[...] que, Yo Comisario, hubiera hecho lo propio [...]". Ofrece su solución ante los hechos lo que, desde su perspectiva, habría dado mejores resultados que los obtenidos a partir de las acciones de Mario. Como aval de su argumento, Carmen construye la perspectiva de lo que ella entiende es una mirada externa, de cualquier persona distinta de Mario: "que a cualquier otro le hubiera bastado, pero tú no, duro, a la Casa de Socorro, [...]". Esta perspectiva externa, en la que Carmen se apoya, es la perspectiva del sentido común, de la sociedad con la que Carmen se siente identificada. La construcción de esta estrategia se recuesta, una vez más, en la selección de la forma -ra como la más apropiada, tal como hemos sostenido hasta aquí. 


\section{Los aparentes contraejemplos}

Las emisiones en las que estos factores no influyen en la selección de las formas deben ser explicadas a la luz del contexto. En nuestro corpus, una mirada atenta nos permite descubrir contextos en los que la base léxica negativa aparece acompañada por la forma $-r a$, lo que pareciera una contradicción respecto de la predicción postulada. Veamos el siguiente ejemplo:

20. [...] al fin y al cabo, te han asignado un ático con tres habitaciones, no han infringido la ley, eres tú el que renuncias, que, a ver, eso sí, dónde íbamos con tres habitaciones, de acuerdo, pero antes de reunirse el Consejo, cuando cubrieron aguas, yo pude hacer algo, Mario, y tú te plantaste, la cabezonada, ya ves Josechu, sus padres visita de los míos de toda la vida, que yo me las hubiera agenciado para quitar hierro a todo aquel asunto del acta, y con Oyarzun y Solórzano, equilicual, recomendaciones no habían de faltarnos, que no sé a qué viene esa testarudez tuya "si das un paso, retiro la solicitud", que te hubiera matado, un mes llorando, que se me retiraron mis cosas y todo, te lo juro, porque el Delegado dio la cara y a poco que Josechu, Oyarzun, Solórzano o el propio Filgueira le hubiesen apoyado, el piso era nuestro, tenlo por seguro, imagínate, seis habitaciones, calefacción y agua caliente central, de cambiarme la vida. (Delibes, 1966, p.107)

El fragmento describe una de las tantas recriminaciones que Carmen realiza a su difunto esposo. En este caso, la acción protagonizada por Mario recibe la evaluación de Carmen, quien relata lo que entiende podría haber sido la solución del tema, en primera persona: "yo me las hubiera agenciado para quitar hierro a todo aquel asunto del acta". Sin embargo, continúa señalando la actitud de Mario, contraria a su posición, en presente: "[...] que no sé a qué viene esa testarudez tuya[...]"; actitud que desata su reacción, a propósito de las consecuencias que la propia Carmen padeció: "[...] que te hubiera matado, un mes llorando, que se me retiraron mis cosas y todo, te lo juro, [...]".

Como vemos, el ejemplo muestra el despliegue de las estrategias descritas más arriba como parte de la justificación subjetiva desarrollada por Carmen, lo que explica la presencia de la forma - ra, en directa relación con el significado postulado. Más adelante, la selección de la forma -se con la que se describe el accionar de terceros en el evento: "[...] porque el Delegado dio la cara y a poco que Josechu, Oyarzun, Solórzano o el propio Filgueira le hubiesen apoyado, el piso era nuestro [...]", acompaña la menor oportunidad de realización que Carmen otorga a la acción que está fuera de su órbita de decisión y que ha generado las consecuencias sobre las que ya se expresó. Las acciones de Mario desencadenan una serie de decisiones adoptadas por otros con consecuencias terribles para Carmen desde su evaluación. Una vez más, la forma seleccionada muestra coherencia respecto del aporte que realiza al contexto que la cobija. 


\section{CONCLUSIONES}

Reflexionar sobre una variación normativa como la que hemos abordado en este trabajo permite superar las descripciones tradicionales que presentan estos usos como "aparentemente similares" y profundizar el análisis sobre el funcionamiento de las variedades que integran el estándar. Entendemos que estos trabajos aportan a la construcción de una gramática superadora capaz de explicar la selección de las formas desde una aproximación a la cognición de los hablantes y se constituyen en insumos de orden lingüístico-teórico para quienes deseen trabajar en la generación de materiales didácticos.

En términos de lingüística aplicada, profundizar el conocimiento sobre una variación inexistente en otras lenguas, como por ejemplo el portugués, lengua con la cual el español se halla en contacto, permitirá elaborar propuestas de intervención didáctica para la enseñanza de español como lengua segunda o extranjera. La experiencia de aquellos docentes que imparten clases de español a hablantes de portugués o italiano, por ejemplo, muestra la dificultad observada en la enseñanza de estas formas del español y la necesidad de mayores herramientas pedagógicas para su abordaje.

Por su parte, estudiar este fenómeno en la variedad peninsular, considerada de manera frecuente como la medida del español -en la que se observa, según algunos autores, una preferencia por la variante -se (Cartagena, 1999)- nos permite verificar que esta variedad comparte las modificaciones en la distribución de las variantes observadas en otras variedades del español americano (Lara Bermejo, 2019; Speranza, 2020) por lo que creemos participa, junto con las formas simples, del inicio de un cambio lingüístico.

En distintas investigaciones hemos trabajado con usos variables presentes en distintos corpus escritos y orales correspondientes a variedades no estandarizadas: producciones de escribientes no expertos (alumnos en proceso de escolarización), producciones pertenecientes al discurso periodístico gráfico (periódicos de las colectividades boliviana y paraguaya en la Argentina) y entrevistas a migrantes. Los trabajos surgidos de estas indagaciones han demostrado la relación entre el fracaso escolar y la variedad lingüística empleada por los estudiantes. En efecto, la utilización de una variedad no estandarizada por parte de los alumnos migrantes aparece como un factor crucial en la tensión producida entre la institución escolar, transmisora del saber lingüístico validado socialmente, y los alumnos. La enseñanza de la variedad estándar, entonces, se transforma en un objetivo que requiere de mayores elementos de descripción sobre su funcionamiento para ser objeto de apropiación por parte de todos los estudiantes, tanto aquellos portadores de una variedad distinta de la impartida en la escuela como por el resto del alumnado (Martínez, 2013, 2015; Martínez et al., 2009; Speranza, 2019; Speranza, Pagliaro y Fernández, 2012; Speranza, Pagliaro y Bravo de Laguna, 2018). 


\section{REFERENCIAS BIBLIOGRÁFICAS}

Delibes, M. [1966] 1980. Cinco horas con Mario. Editorial Claretiana.

Cartagena N. (1999). Los tiempos compuestos. En I. Bosque y V. Demonte (Dir.), Gramática descriptiva de la lengua española. (Vol, II) (pp. 2935-2975). Real Academia Española, Espasa Calpe.

Charaudeau P. y Maingueneau D. (2005) Diccionario de Análisis del Discurso. Amorrortu editores.

García, E. (1985). Shifting variation. Lingua 67, 189-224.

García, E. (1995). Frecuencia (relativa) de uso como síntoma de estrategias etnopragmáticas. En K. Zimmermann (Ed.), Lenguas en contacto en Hispanoamérica (pp. 51-72). Iberoamericana / Vervuert.

García, E. (1997). La portée de la variabilité. En F. Godet (Ed.), La variation on syntaxe Langue Française (pp. 30-47). Larousse.

Lara Bermejo, V. (2019). El pretérito imperfecto de subjuntivo en la Península Ibérica del siglo XX. Verba, 46, 313-338.

Lyons, J. (1997). Semántica lingüística. Paidós.

Martínez, A. (1991). Tiempos verbales en el discurso hipotético en el habla de Buenos Aires. Actas del I Congreso del español de América (pp. 519-526). Universidad de Valladolid.

Martínez, A. (1993). Emisiones contrafactuales e intención comunicativa. Actas del X Congreso Internacional de la ALFAL, (pp. 201-205). Universidad Nacional Autónoma de México.

Martínez, A. (2000). Lenguaje y Cultura. Estrategias etnopragmáticas en el uso de los pronombres clíticos lo, la y le en la Argentina en zonas de contacto con lenguas aborígenes. [Tesis doctoral], Universidad de Leiden.

Martínez, A. (2013). (Comp.) Huellas teóricas en la práctica pedagógica. El dinamismo lingüístico en el aula multicultural. Edulp.

Martínez, A. (2015). Las escuelas del Mercosur: la trama de las gramáticas y el concepto de identidades dinámicas. En E. Narvaja de Arnoux y R. Bein (Eds), Política lingüística y enseñanza de lenguas (pp. 109-134). Biblos. 
Martínez, A. (2019). El “juego” intraparadigmático: Una mirada al uso actual de los clíticos en Buenos Aires. En: N. Stern, R. Otheguy, W. Reid \& J. Sackler (Eds.), Columbia School Linguistics in the 21st Century (pp. 199-216). Benjamin.

Martínez, A; Gualdieri, B y Oberti, L. (1998). Alternancia y frecuencia de uso en las condicionales contrafactuales de pasado: una interpretación cualitativa. En Actas del IX Congreso Internacional de la Asociación Lingüística y Filológica de América Latina (ALFAL), (pp. 97-106). Universidad Estatal de Campinas e Instituto de Estudios del Lenguaje.

Martínez, A. Speranza A. y Fernández, G. (2009). El entramado de los lenguajes. La Crujía.

Real Academia Española y Asociación de Academias de la Lengua. 2010. Nueva gramática de la lengua española. Espasa Calpe.

Speranza, A. (2014). La evidencialidad en el español americano. La expresión lingüística de la perspectiva del hablante. Iberoamericana.

Speranza, A. (2019). La urdimbre del habla urbana. El caso de la educación superior. Forma y Función, 32 (2), 299- 314 https://doi.org/10.15446/fyf.v32n2.80825

Speranza, A. (2020). Sobre tendencias gramaticales y distribuciones observadas. La alternancia del imperfecto del subjuntivo como estrategia evidencial en el español de la Argentina. Studi italiani di lingüística teorica e applicata, XLIX (1). http://www. studitlinguisticateoricappl.it/wp-content/uploads/2020/11/4-Speranza.pdf.

Speranza, A.; Pagliaro, M. y Fernández, G. (2012) Identidades lingüísticas y culturales en contexto educativos. Imprex Ediciones.

Speranza, A.; Pagliaro, M. y Bravo de Laguna, G. (2018). La enseñanza del español en contextos de diversidad lingüística. En Ministerio de Educación, Cultura, Ciencia y Tecnología, La investigación en los institutos de Formación Docente. Volumen 3: Inclusión, trayectorias educativas y aprendizajes de los estudiantes (pp. 196-219). Ministerio de Educación, Cultura, Ciencia y Tecnología.https://cedoc.infd.edu.ar/wpcontent/uploads/2019/12/VOLUMEN-3-INCLUSION-TRAYECTORIAS-EDUCATIVAS-YAPRENDIZAJES-DE-LOS-ESTUDIANTES.pdf 


\begin{abstract}
${ }^{1}$ Doctora en Letras por la Universidad de Leiden (Países Bajos), es Profesora extraordinaria en carácter de Consulta de la Universidad Nacional de La Plata. Es directora del Centro de Estudios e Investigaciones Lingüísticas (CEIL), coordinadora de la Maestría en Lingüística de la misma Universidad y responsable de la Delegación Regional de la Asociación de Lingüística y Filología para la América Latina (ALFAL) y de la subsede La Plata de la Cátedra UNESCO, para el mejoramiento y equidad de la Lectura y la Escritura. Desde hace veinte años dirige el programa de investigación Etnopragmática que ha contado, desde su inicio, con doctorandos en diferentes universidades del país y del exterior y desde 2004 participa activamente en el núcleo del Programa internacional "El español de los Andes" que se lleva a cabo en las Universidades de Friburgo y de Montreal y del Programa Internacional "Contacto del español con otras lenguas" que, con base en la Universidad Autónoma de Madrid, reúne investigadores de universidades españolas y americanas.
\end{abstract}

Dirige (junto a Adriana Speranza) la serie de libros Discutir el lenguaje y es curadora del Proyecto CORdEMIA (Corpus de español de migrantes en la Argentina), ambos de la UNLP.

Su producción científica se centra en estudios etnopragmáticos.

${ }^{2}$ Obtuvo el Posdoctorado en el Programa de Posdoctorado en Ciencias Humanas de la Facultad de Filosofía y Letras de la Universidad de Buenos Aires y el Doctorado en Lingüística por la misma Universidad. Es Profesora Titular de Lingüística en la Licenciatura en Comunicación Social de la Universidad Nacional de Moreno y Profesora Adjunta a cargo de la Cátedra de Lingüística en la Universidad Nacional de La Plata. Es Investigadora Adjunta de CONICET. La UNM coordina el Programa de Estudios Lingüísticos perteneciente al Centro de Estudios de Medios y Comunicación; es Directora Académica de la Carrera de Especialización en Lectura y Escritura; coordina la Subsede UNM de la Cátedra UNESCO y se desempeña como CoordinadoraVicedecana de la Licenciatura en Comunicación Social. Desarrolla su tarea docente y de investigación en el campo de la Lingüística y de la Sociolingüística, específicamente, su trabajo se orienta hacia la variación lingüística, el contacto de lenguas y las migraciones. 